\title{
Sistem Informasi Pelayanan Berbasis Web pada Dinas Koperasi dan UKM Kabupaten Purbalingga
}

\author{
Riyan Latifahul Hasanah
}

\begin{abstract}
Based on data in 2017 the number of cooperatives in Purbalingga Regency is 231 units and MSMEs are 127,123 units. With a large number of cooperatives and MSMEs managed, the Purbalingga Regency Cooperative and SME Office are demanded to be able to provide fast and maximum services and to establish good communication with each cooperative and MSMEs. But from the facts that are happening at the moment, these two things cannot be done to the maximum. Noted from that number, only about 75 MSMEs were intensively fostered. So the Purbalingga Regency Cooperative and UKM Office need for media to provide immediate communication and information to the public. One solution that can be chosen is to create a website that can provide people to get services, communicate and access information online that can be done anytime and anywhere. The software development method used is the waterfall model with five stages, namely: needs analysis, design, coding, testing and support or maintenance. With this website, it is easy for the Purbalingga Regency Cooperative and SME Office to provide online services and manage cooperative and MSME data. The website that is present can provide added value promotions for cooperatives and SMEs in the District of Purbalingga.
\end{abstract}

Index Terms-Department of Cooperatives and SMEs; Information Systems; Online Services; Website.

Abstrak--Berdasarkan data pada tahun 2017 jumlah koperasi yang ada di Kabupaten Purbalingga sejumlah 231unit dan UMKM sejumlah 127.123 unit. Dengan banyaknya jumlah koperasi dan UMKM yang dikelola, Dinas Koperasi dan UKM Kabupaten Purbalingga dituntut untuk dapat memberikan pelayanan yang cepat dan maksimal serta dapat membangun komunikasi yang baik dengan setiap koperasi dan UMKM. Namun dari fakta yang terjadi saat ini kedua hal tersebut belum dapat diwujudkan secara maksimal.Tercatat dari jumlah tersebut hanya sekitar 75 UMKM yang dibina secara intensif.Maka Dinas Koperasi dan UKM Kabupaten Purbalingga memerlukan sebuah media pelayanan sekaligus media komunikasi dan informasi kepada masyarakat.Salah satu solusi yang dapat dipilih yaitu dengan dibuatnya website yang dapat memudahkan masyakat untuk mendapatkan pelayanan, melakukan komunikasi dan mengakses informasi secara online yang

Riyan Latifahul Hasanah is with the Faculty of Technology Information Universitas Bina Sarana Informatika, Jakarta, Indonesia (email riyan.rlt@bsi.ac.id) dapat dilakukan kapan saja dan dimana saja. Metode pengembangan perangkat lunak digunakan yaitu model waterfall dengan lima tahapan, yaitu: analisa kebutuhan, desain, pengkodean, pengujian dan pendukung atau pemeliharaan. Dengan adanya website ini memudahkan pihak Dinas Koperasi dan UKM Kabupaten Purbalingga dalam memberikan pelayanan online serta mengelola data koperasi dan data UMKM.Bahkan kehadiran website ini dapat memberikan nilai tambah promosi bagi koperasi dan UMKM yang ada di wilayah Kabupaten Purbalingga.

Kata Kunci-Dinas Koperasi dan UKM; Pelayanan Online; Sistem Informasi; Website.

\section{PENDAHULUAN}

$\mathrm{T}$ EKNOLOGI merupakan hal yang tidak dapat dipisahkan dari kehidupan manusia, bahkan teknologi semakin berkembang dari waktu ke waktu. Salah satu bentuk teknologi yang paling populer saat ini adalah internet, dimana dalam perkembangannya internet telah digunakanpada hampir semua bidang kehidupan.

Penggunaan teknologi internet dalam lingkungan pemerintahan telah melahirkan suatu aplikasi yang disebut e-government.E-government mengacu kepada penyampaian informasi dan pelayanan online pemerintah melalui media internet atau media digital lainnya [1]. Namun meskipun teknologi internet telah merambah bidang pemerintahan, tidak semua lembaga pemerintahan di Indonesia memanfaatkan teknologi internet ini dengan maksimal. Salah satunya yang terjadi pada Dinas Koperasi dan UKM Kabupaten Purbalingga.

Berdasarkan data yang diperoleh dari Dinas Koperasi dan UKM Kabupaten Purbalingga menunjukan bahwa pada tahun 2017 jumlah koperasi yang ada di Kabupaten Purbalingga sejumlah 231 unit dan UMKM sejumlah 127.123 unit.Dengan banyaknya jumlah koperasi dan UMKM yang dikelola, Dinas Koperasi dan UKM Kabupaten Purbalingga dituntut untuk dapat memberikan pelayanan yang cepat dan maksimal serta dapat membangun komunikasi yang baik dengan setiap koperasi dan UMKM.

Namun dari fakta yang terjadi saat ini kedua hal tersebut belum dapat diwujudkan secara maksimal. Sebagai contoh, koperasi atau UMKM harus melewati prosedur yang cukup panjang dan menyita waktu untuk 
mendapatkan sebuah surat tugas. Selain itu komunikasi dan sosialisasi kegiatan yang masih kurang mengakibatkan banyak koperasi yang "mati suri" atau tidak lagi produktif, dan hanya sekitar 75 UMKM dari 127.123 UMKM yang dibina secara intensif oleh Dinas Koperasi dan UKMKabupaten Purbalingga.

Dari uraian diatas dapat disimpulkan bahwa Dinas Koperasi dan UKM Kabupaten Purbalingga memerlukan sebuah media pelayanan sekaligus media komunikasi dan informasi kepada masyarakat. Salah satu solusi yang dapat dipilih yaitu dengan dibuatnya website yang dapat memudahkan masyakat untuk mendapatkan pelayanan, melakukan komunikasi dan mengakses informasi secara online yang dapat dilakukan kapan saja dan dimana saja.

Dengan kehadiran website pelayanan ini, peran Dinas Koperasi dan UKM Kabupaten Purbalingga untuk membina dan mengembangkan koperasi dan UMKM akan menjadi lebih baik dan maksimal, salah satunya dengan pelayanan yang lebih cepat. Selain itu juga dapat memberikan pengetahuan dan informasi kepada masyarakat luas mengenai berbagai koperasi dan UMKM yang ada di Kabupaten Purbalingga.

\section{LANDASAN TEORI}

\section{A. Sistem Informasi}

Sistem informasi adalah kumpulan elemen yang saling berhubungan satu sama lain yang membentuk suatu kesatuan untuk mengintegrasikan data, memproses dan menyimpan serta mendistribusikan informasi [2].

Sistem informasi merupakan kombinasi teratur dari orang-orang,perangkat keras (hardware), perangkat lunak (software), jaringan komunikasi dan sumber daya data yang mengumpulkan, mengubah dan menyebarkan informasi dalam sebuah organisasi [3].

\section{B. Pelayanan}

Pelayanan adalah pemberian jasa baik oleh pemerintah, pihak swasta atas nama pemerintah ataupun pihak swasta kepada masyarakat, dengan atau tanpa pembayaran guna memenuhi kebutuhan dan kepentingan masyarakat [4].

Pelayanan adalah setiap tindakan atau kegiatan yang dapat ditawarkan oleh satu pihak kepada pihak lain, pada dasarnya tidak berwujud dan tidak mengakibatkan kepemilikan apa pun [5].

\section{Website}

Website atau situs dapat diartikan sebagai kumpulan halaman yang menampilkan informasi data teks, data gambardiam atau gerak, data animasi, suara, video dan gabungan dari semuanya baik yang bersifat statis maupun dinamis yang membentuk suatu rangkaian bangunan yang saling terkait dimana masing-masing dihubungkan dengan jaringan-jaringan halaman (hyperlink)[6].

Secara garis besar web bisa digolongkan menjadi tiga jenis [7]:
1. Website statis adalah web yang mempunyai halaman tidak berubah.Artinya, untuk melakukan perubahan pada suatu halaman dilakukan secara manual dengan mengedit code yang menjadi struktur dari website tersebut.

2. Website dinamis merupakan website yang secara struktur diperuntukkan untuk update sesering mungkin. Biasanya selain halaman utama yang bisa diakses oleh pengguna pada umumnya, juga disediakan halaman backend untuk mengedit konten dari website.

3. Website Interaktif merupakan web yang saat ini memang sedang 'booming'. Salah satu contoh website interaktif adalah blog dan forum.

\section{Model Pengembangan Perangkat Lunak}

Software Development Life Cycle (SDLC) adalah proses pengembangan atau mengubah suatu sistem perangkat lunak dengan menggunakan model-model dan metodologi yang digunakan orang untuk mengembangkan sistem-sistem perangkat lunak sebelumnya (berdasarkan best practice atau cara-cara yang sudah teruji baik) [8].

Penelitian ini menggunakan metode pengembangan perangkat lunak model waterfall. Model ini sering digunakan karena dapat dengan mudah dikembangkan sesuai dengan kebutuhan. Model waterfall ditampilkan pada Gambar 1.

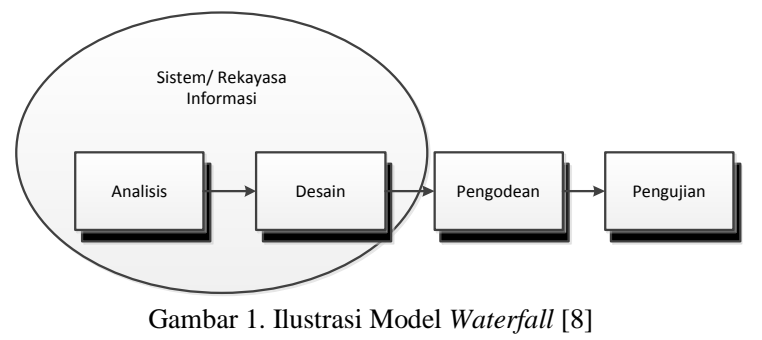

\section{E. Logical Record Structure}

Logical Record Structure (LRS) merupakan representasi dari struktur record-record pada tabel-tabel yang terbentuk dari hasil relasi antar himpunan entitas pada diagram Entity Relationship [9].

\section{F. Pengujian Web}

Pengujian perangkat lunak adalah sebuah atau serangkaian proses yang dirancang untuk memastikan bahwa program yang dibuat telah berjalan sesuai dengan tujuan yang diinginkan [10]. Teknik pengujian yang digunakan pada penelitian ini adalah black box testing.

Black box testing adalah menguji perangkat lunak dari segi spesifikasi fungsional tanpa menguji desain dan kode program. Pengujian dimaksudkan untuk mengetahui apakah fungsi-fungsi, masukan, dan keluaran dari perangkat lunak sesuai dengan spesifikasi yang dibutuhkan [8].

\section{G. Penelitian Terkait}

Sistem informasi pelayanan berbasis web sudah mulai digunakan untuk menyelesaikan permasalahanpermasalahan di berbagai lembaga pemerintahan.

Untuk mendukung pelayanan di kantor desa atau 
kelurahan, sistem informasi berbasis website telah banyak diaplikasikan. Misalnya pada penelitian [11] memberikan kemudahan bagi masyarakat yang ingin membuat surat rekomendasi dan surat keterangan secara online. Penelitian lainnya [12] membangun sistem informasi untuk memberikan pelayanan kepada masyarakat, seperti pelayanan pembuatan surat kelahiran, surat kematian maupun surat mutasi melalui website sehingga akan lebih menghemat waktu.

Sementara itu dalam penelitian [13], sistem yang dibangun merupakan sistem untuk pelayanan dan pengelolaan data penduduk, serta pengelolaan surat di lingkup kecamatan.

Pada penelitian lainnya [14], website yang dihasilkan memberikan kemudahan bagi masyarakat untuk menyampaikan keluhan terkait kondisi jalan dan jembatan di Kabupaten Kampar, juga membantu pegawai dalam pengelolaan laporan pengaduan, perbaikan serta pembangunan jalan dan jembatan.

Selain itu penelitian [15] menyimpulkan bahwa dengan adanya sistem informasi berbasis web akan mempermudah masyarakat serta pihak yang berkepentingan untuk memperoleh informasi yang dibutuhkan untuk proses pembuatan izin usaha kapan saja dan dimana saja melalui media website sehingga lebih cepat, efektif dan efisien.

Website yang dibangun dalam penelitian ini mengakomodir beberapa penelitan diatas, seperti pengajuan surat, pengelolaan data, pengelolaan surat, konsultasi atau laporan masyarakat, pusat informasi serta fasilitas pembuatan laporan bagi karyawan Dinas Koperasi dan UKM Kabupaten Purbalingga.

\section{METODE PENELITIAN}

Metode pengembangan perangkat lunak digunakan yaitu model waterfall dengan lima tahapan, yaitu:

\section{A. Analisa Kebutuhan}

Pada tahap ini sistem yang akan dibuat dikaji dan dibuat berdasarkan hasil pengamatan dilapangan dan wawancara langsung terhadap pegawai Dinas Koperasi dan UKM Kabupaten Purbalingga.Analisa mengenai prosedur pelayanan dilakukan agar nantinya website yang dihasilkan sesuai dengan kebutuhan dan harapan

\section{B. Desain}

Pada tahap desain, kebutuhan yang sudah dianalisa dituangkan kedalam bentuk desain antar muka dan desainstruktur data.

Desain antar muka atau tampilan website terdiri dari halaman front end dan back end. Halaman front end adalah halaman website yang dapat diakses oleh pengunjung. Sedangkan halaman back end adalah halaman website yang hanya dapat diakses oleh adminuntuk melakukan manajemen website.

Desain struktur data dilakukan dengan mendesain tabel-tabel di database. Halini dilakukan agar kebutuhan system dapat diimplementasikan menjadi program pada tahap pengkodean.

\section{Pengkodean}

Pembuatan kode-kode program dilakukan agar desainyang telah dibuat pada tahap sebelumnya dapat diimplementasikan menjadi program utuh untuk dapat dimanfaatkan sesuai tujuannya. Kode program yang digunakan antara lain HTML, PHP, CSS dan Javascript.

\section{Pengujian}

Keseluruhan fungsiwebsite yang telah terbentuk perlu diuji agar bisa dipastikan bahwa keluaran yang dihasilkan sistem sesuai dengan yang diinginkan. Pengujian juga dilakukan untuk meminimalisir kesalahan (error). Pengujian dilakukan menggunakan blackbox testing (pengujian kotak hitam).

\section{E. Pendukung atau Pemeliharaan}

Tahap pendukung atau pemeliharaan dilakukan untuk menangani dan memperbaiki kesalahan-kesalahan yang muncul ketika website telah digunakan oleh pengguna, serta tidak terdeteksi pada tahap pengujian.

\section{PEMBAHASAN}

\section{A. Analisa Kebutuhan}

\section{1) Kebutuhan Pengguna}

Kebutuhan pengguna berisi hal-hal apa saja yang dibutuhkan oleh masing-masing pengguna. Kebutuhan pengguna tersebut antara lain:

a. Kebutuhan pengunjung

Pengunjung website dapat melihat profil Dinas Koperasi dan UKM Kabupaten Purbalingga, program kegiatan apa saja yang direncanakan, data-data koperasi dan UMKM yang ada di wilayah Kabupaten Purbalingga, data penerima bantuan, galeri foto dari kegiatan yang sudah dilaksanakan, beritaberita mengenai dunia koperasi dan UMKM, memberikan komentar pada berita, melakukan pendaftaran anggota koperasi atau UMKM, melakukan layanan konsultasi usaha online, mengisi formulir buku tamu, memberikan suara dalam jejak pendapat, dan juga mendownload file yang sudah disediakan.

b. Kebutuhan anggota

Untuk mengakses halaman anggota, anggota harus login terlebih dahulu. Di halaman ini, anggota dapat mengubah data dan profil koperasi atau UMKM yang dikelolanya, melakukan konsultasi usaha privasi yang tidak akan dipublikasikan di website, melakukan layanan pengajuan surat online, menerima informasi-informasi serta mengubah password.

c. Kebutuhan admin

Admin harus diberikan akses dan tools untuk melakukan manajemen data dan informasi yang ada di website. Data tersebut antara lain data berita, data komentar, data buku tamu, data admin, data koperasi, data UMKM, data penerima bantuan, data file download, data album dan foto, data layanan pengajuan surat, data layanan konsultasi usaha, data profil 
dinas dan profil anggota, data program kegiatan, data informasi anggota, data kontak website dan data link terkait. Seperti anggota, admin juga diharuskan untuk login terlebih dahulu untuk mengecek apakah pihak tersebut berhak mengakses halaman admin atau tidak. Selain melakukan perubahan data, admin juga diharuskan untuk merespon aktifitas pengunjung, seperti memberikan jawaban atas pertanyaan konsultasi yang diberikan pengunjung, menanggapi pengajuan surat yang diberikan anggota dan menanggapi permintaan pendaftaran anggota. Admin juga diberikan akses untuk mengubah profil serta passwordnya sendiri.

2) Kebutuhan Sistem

Kebutuhan sistem berisi hal-hal apa saja yang dibutuhkan dalam rangka pembuatan sistem pelayanan online pada Dinas Koperasi dan UKM Kabupaten Purbalingga. Kebutuhan sistem tersebut antara lain:

a. Kebutuhan data

Data-data yang diperlukan dalam sistem ini antara lain: data $a d m i n$, data album foto, data berita, data buku tamu, data penerima bantuan, data koperasi, data UMKM, data file download, data foto, data informasi anggota, data jejak pendapat, data komentar, data konsultasi, data kontak, data link terkait, data profil instansi, data profil anggota, data program kegiatan dan data surat

b. Akses level

Website harus dapat melakukan penyaringan pengguna dengan menggunakan akses level.Maksudnya para pengguna dapat mengakses website sejauh hak akses yang diberikan kepada pengguna tersebut. Penyaringan pengguna ini dilakukan dengan adanya login pengguna menggunakan username dan password. Beberapa hak akses tersebut antara lain:

(1) Hak akses untuk pengunjung

Pengunjung hanya dapat melihat konten terbatas pada apa yang ditampilkan di halaman front end. Pengunjung dapat melakukan interaksi langsung pada website dengan adanya layanan pendaftaran anggota, layanan konsultasi usaha online, jejak pendapat, komentar berita dan buku tamu pengunjung.

(2) Hak akses untuk anggota

Hak akses anggota diberikan kepada pelaku koperasi dan UMKM di Kabupaten Purbalingga yang sebelumnya telah mengisi formulir pendaftaran anggota dan telah disetujui oleh admin.Pengunjung website yang ingin mengakses fasilitas khusus anggota seperti layanan pengajuan surat online harus melakukan login anggota terlebih dahulu.

(3) Hak akses untuk admin
Hak akses admin diberikan kepada pihak yang dipercaya untuk melakukan pengelolaan website, yaitu untuk melihat, menambahkan, mengubah dan menghapus data serta informasi website. Halaman admin ini dapat diakses dengan mengetikkan URL halaman admin yang hanya diketahui oleh admin, kemudian login menggunakan username dan password admin.

c. Keamanan website

Untuk menjaga agar konten website dapat diakses sesuai dengan hak yang diberikan maka diperlukan halaman login baik untuk anggota maupun admin dengan menginputkan username dan password. Jika pengguna tidak berwenang, maka halaman yang dimaksud tidak akan ditampilkan beserta seluruh data dan informasinya. Password perlu dienkripsi dengan menggunakan fungsi md5 di database. Pada form login juga disediakan captcha untuk mengecek apakah pengguna yang melakukan login manusia atau mesin.

\section{B. Logical Record Structure (LRS)}

LRS menampilkan tabel-tabel pada database yang berelasi. Anggota merupakan pengurus koperasi dan UKM. Anggota dapat mengajukan dua jenis surat, yaitu surat tugas dan surat pengantar. Anggota juga dapat melakukan konsultasi, dimana pertanyaan konsultasi akan dijawab oleh admin. LRS ditampilkan pada Gambar 2.

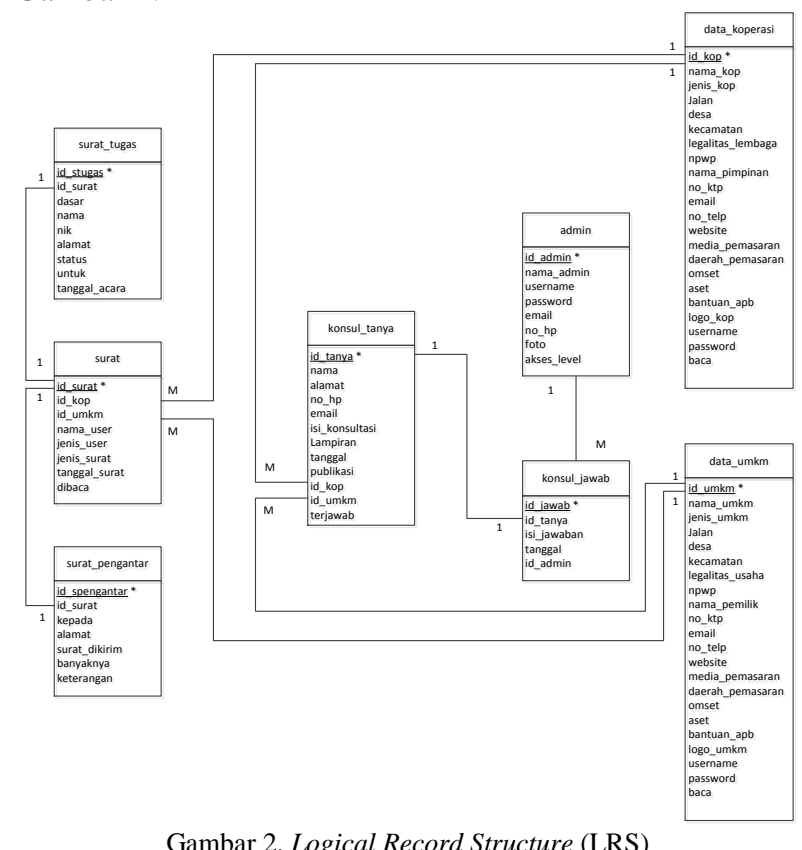

\section{Implementasi Sistem}

Implementasi sistem merupakan tahapan dalam menerapkan sistem yang telah dibangun.

1) Implementasi halaman beranda pengunjung Halaman pengunjung adalah halaman yang dapat diakses secara bebas oleh masyarakat tanpa harus login. Di halaman ini ditampilkan informasiinformasi umum, seperti profil, berita, galeri 
kegiatan, buku tamu, konsultasi, dan sebagainya. Gambar 3 adalah tampilan beranda pengunjung.

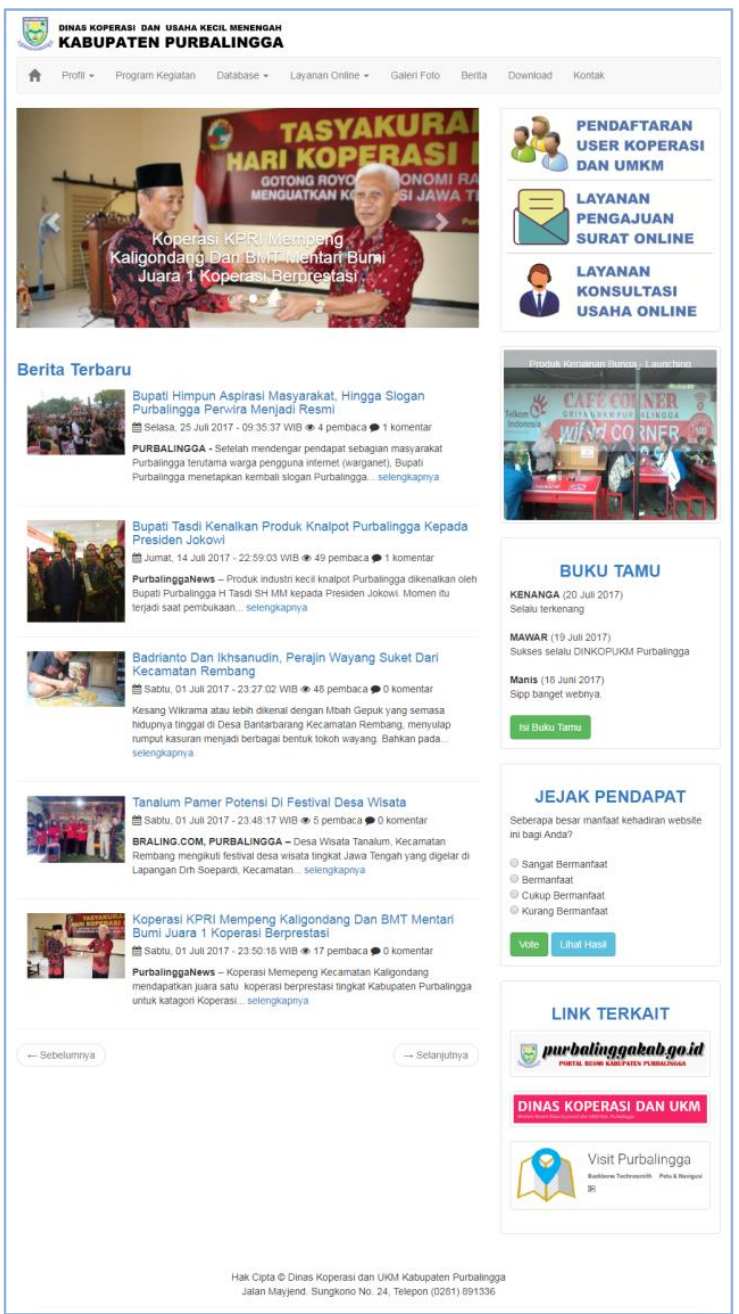

Gambar 3. Implementasi Halaman Beranda Pengunjung

2) Implementasi halaman login anggota

Untuk masuk ke halaman anggota, anggota harus login terlebih dahulu dengan menginputkan jenis anggota, username, password dan kode captcha. Gambar 4 adalah tampilan halaman login anggota.

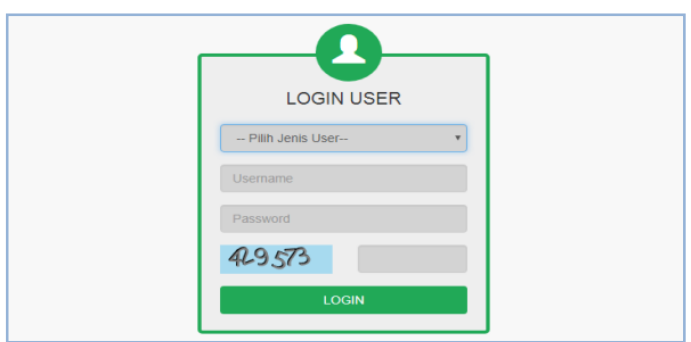

Gambar 4. Implementasi HalamanLogin Anggota

3) Implementasi halaman pengajuan surat anggota Anggota dapat mengajukan surat pengantar dan surat anggota melalui halaman pengajuan surat. Riwayat surat yang telah diajukan juga akan ditampilkan. Gambar 5 adalah tampilan halaman pengajuan surat.

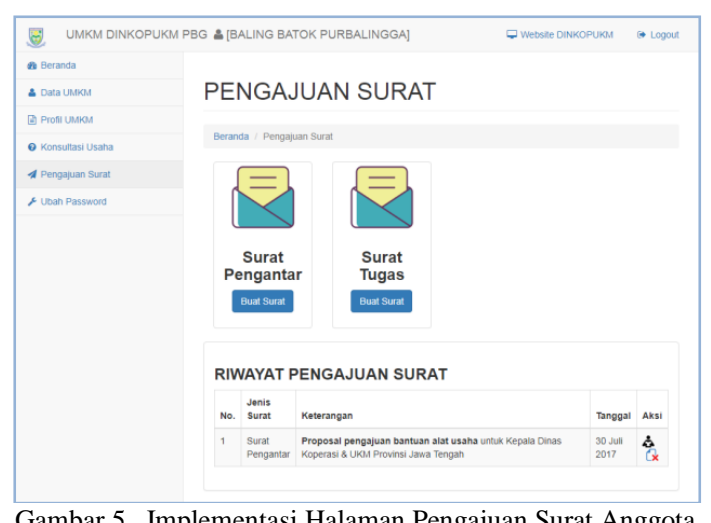

Gambar 5. .Implementasi Halaman Pengajuan Surat Anggota

4) Implementasi halaman beranda admin

Halaman admin hanya dapat diakses oleh admin, dan digunakan untuk melakukan manajemen seluruh data yang ada di dalam website. Gambar 6 adalah tampilan beranda admin.

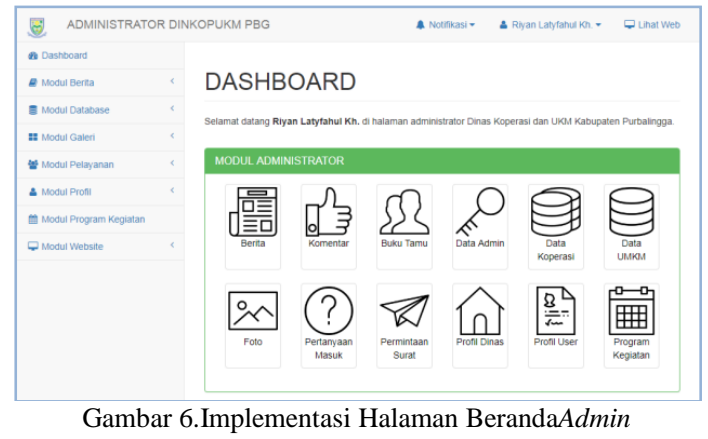

\section{Pengujian}

Pengujian masing-masing unit dilakukan menggunakan teknik black box testing. Berikut ini adalah hasil pengujian dari halaman login anggota.

Tabel 1. Black Box Testing Halaman LoginAnggota

\begin{tabular}{|c|c|c|c|c|}
\hline $\begin{array}{l}\text { Skenario } \\
\text { Pengujian }\end{array}$ & Test Case & $\begin{array}{c}\text { Hasil } \\
\text { yang } \\
\text { Diharapk } \\
\text { an } \\
\end{array}$ & $\begin{array}{l}\text { Hasil } \\
\text { Penguji } \\
\text { an }\end{array}$ & $\begin{array}{l}\text { Kesim } \\
\text { pulan }\end{array}$ \\
\hline $\begin{array}{l}\text { Jenis } \text { user, } \\
\text { username, } \\
\text { password, dan } \\
\text { kode captcha } \\
\text { tidak diisi, lalu } \\
\text { klik login }\end{array}$ & $\begin{array}{l}\text { Jenis : (kosong) } \\
\text { Username: } \\
\text { (kosong) } \\
\text { Password: } \\
\text { (kosong) } \\
\text { Captcha: } \\
\text { (kosong) }\end{array}$ & $\begin{array}{l}\text { Sistem } \\
\text { akan } \\
\text { menolak } \\
\text { akses } \\
\text { halaman } \\
\text { anggota. }\end{array}$ & $\begin{array}{l}\text { Sesuai } \\
\text { harapa } \\
\mathrm{n}\end{array}$ & Valid \\
\hline $\begin{array}{l}\text { Jenis } \text { user dan } \\
\text { username diisi, } \\
\text { password dan } \\
\text { kode captcha } \\
\text { tidak diisi, lalu } \\
\text { klik login }\end{array}$ & $\begin{array}{l}\text { Jenis : Koperasi } \\
\text { Username: } \\
\text { kop-argo17 } \\
\text { Password: } \\
\text { (kosong) } \\
\text { Captcha: } \\
\text { (kosong) }\end{array}$ & $\begin{array}{l}\text { Sistem } \\
\text { akan } \\
\text { menolak } \\
\text { akses } \\
\text { halaman } \\
\text { anggota. }\end{array}$ & $\begin{array}{l}\text { Sesuai } \\
\text { harapa } \\
\mathrm{n}\end{array}$ & Valid \\
\hline $\begin{array}{l}\text { Jenis } \text { user, } \\
\text { username dan } \\
\text { password diisi, } \\
\text { kode captcha } \\
\text { tidak diisi, lalu } \\
\text { klik login }\end{array}$ & $\begin{array}{l}\text { Jenis : Koperasi } \\
\text { Username: } \\
\text { kop-argo17 } \\
\text { Password: } \\
\text { argowalu } \\
\text { Captcha: } \\
\text { (kosong) }\end{array}$ & $\begin{array}{l}\text { Sistem } \\
\text { akan } \\
\text { menolak } \\
\text { akses } \\
\text { halaman } \\
\text { anggota }\end{array}$ & $\begin{array}{l}\text { Sesuai } \\
\text { harapa } \\
\mathrm{n}\end{array}$ & Valid \\
\hline $\begin{array}{l}\text { Jenis } \text { user tidak } \\
\text { diisi, username, } \\
\text { password dan } \\
\text { kode captcha }\end{array}$ & $\begin{array}{l}\text { Jenis : (kosong) } \\
\text { Username: } \\
\text { kop-argo17 } \\
\text { Password: }\end{array}$ & $\begin{array}{l}\text { Sistem } \\
\text { akan } \\
\text { menolak } \\
\text { akses } \\
\end{array}$ & $\begin{array}{l}\text { Sesuai } \\
\text { harapa } \\
\mathrm{n}\end{array}$ & Valid \\
\hline
\end{tabular}




\begin{tabular}{|c|c|c|c|c|}
\hline $\begin{array}{l}\text { diisi, lalu klik } \\
\text { login }\end{array}$ & $\begin{array}{l}\text { argowalu } \\
\text { Captcha: } \\
027470\end{array}$ & $\begin{array}{l}\text { halaman } \\
\text { anggota }\end{array}$ & & \\
\hline $\begin{array}{l}\text { Mengetikkan } \\
\text { salah pada } \\
\text { username dan } \\
\text { password, jenis } \\
\text { user dan kode } \\
\text { captcha benar, } \\
\text { lalu klik login }\end{array}$ & $\begin{array}{l}\text { Jenis : Koperasi } \\
\text { Username : } \\
\text { kop-argo } \\
\text { Password : argo } \\
\text { Captcha: } \\
027470\end{array}$ & $\begin{array}{l}\text { Sistem } \\
\text { akan } \\
\text { menolak } \\
\text { akses } \\
\text { halaman } \\
\text { anggota. }\end{array}$ & $\begin{array}{l}\text { Sesuai } \\
\text { harapa } \\
\mathrm{n}\end{array}$ & Valid \\
\hline $\begin{array}{l}\text { Jenis } \text { user } \\
\text { benar, } \\
\text { mengetikkan } \\
\text { benar pada } \\
\text { username dan } \\
\text { password, kode } \\
\text { captcha salah, } \\
\text { lalu klik login } \\
\end{array}$ & $\begin{array}{l}\text { Jenis : Koperasi } \\
\text { Username : } \\
\text { kop-argo17 } \\
\text { Password: } \\
\text { argowalu } \\
\text { Captcha: } \\
027471\end{array}$ & $\begin{array}{l}\text { Sistem } \\
\text { akan } \\
\text { menolak } \\
\text { akses } \\
\text { halaman } \\
\text { anggota }\end{array}$ & $\begin{array}{l}\text { Sesuai } \\
\text { harapa } \\
\mathrm{n}\end{array}$ & Valid \\
\hline $\begin{array}{l}\text { Jenis } \text { user } \\
\text { benar, } \\
\text { mengetikkan } \\
\text { benar pada } \\
\text { username, } \\
\text { password dan } \\
\text { kode captcha, } \\
\text { lalu klik login }\end{array}$ & $\begin{array}{l}\text { Jenis : Koperasi } \\
\text { Username: } \\
\text { kop-argo17 } \\
\text { Password: } \\
\text { argowalu } \\
\text { Captcha: } \\
027470\end{array}$ & $\begin{array}{l}\text { Sistem } \\
\text { akan } \\
\text { menerim } \\
\text { a akses } \\
\text { halaman } \\
\text { anggota }\end{array}$ & $\begin{array}{l}\text { Sesuai } \\
\text { harapa } \\
\mathrm{n}\end{array}$ & Valid \\
\hline
\end{tabular}

\section{PENUTUP}

Berdasarkan hasil dan pembahasan mengenai sistem informasi pelayanan berbasis web pada Dinas Koperasi dan UKM Kabupaten Purbalingga, dapat disimpulkan bahwa sistem ini memberikan kemudahan bagi masyarakat Kabupaten Purbalingga dalam memperoleh layanan pengajuan surat, layanan konsultasi usaha, serta informasi mengenai Dinas Koperasi dan UKM Kabupaten Purbalingga.

Dengan adanya website ini memudahkan pihak Dinas Koperasi dan UKM Kabupaten Purbalingga dalam memberikan pelayanan online serta mengelola data koperasi dan data UMKM.

Website ini juga dapat digunakan sebagai sarana untuk meningkatkan komunikasi antara Dinas Koperasi dan UKM Kabupaten Purbalingga terhadap masyarakat luas. Bahkan website ini dapat memberikan nilai tambah promosi bagi koperasi dan UMKM yang ada di wilayah Kabupaten Purbalingga.

Untuk mengoptimalkan fungsi website yang telah dibangun, dibutuhkan administrator yang bertanggung jawab dan mampu untuk mengelola semua data-data yang ada pada website.Administrator harus selalu memperbaharui konten website serta memeriksa secara berkalanotifikasi aktivitas website.Selain itu sistem masih perlu dikembangkan dengan menambahkan fiturfitur lain yang masih belum tersedia, seperti misalnya informasi produk-produk yang dihasilkan oleh UMKM.

\section{REFERENSI}

[1] Sosiawan, E. A. (2008) 'Tantangan dan Hambatan dalam Implementasi E-Government di Indonesia', in Seminar Nasional Informatika, pp. 99-108. Available at: http://jurnal.upnyk.ac.id/index.php/semnasif/article/view/760.

[2] Sitohang, H. T. (2018) 'Sistem Informasi Pengagendaan Surat Berbasis Web Pada Pengadilan Tinggi Medan', Journal of Informatic Pelita Nusantara, 3(1), pp. 6-9. Available at: http://ejurnal.pelitanusantara.ac.id/index.php/JIPN/article/viewFile/276/ 174.

[3] Firman, A., Wowor, H. F. and Najoan, X. (2016) 'Sistem
Informasi Perpustakaan Online Berbasis Web', E-Journal Teknik Elektro dan Komputer, 5(2). Available at: https://ejournal.unsrat.ac.id/index.php/elekdankom/article/view/ 11657.

[4] Sundari, J. (2016) 'Sistem Informasi Pelayanan Puskesmas Berbasis Web', IJSE - Indonesian Journal on Software Engineering, 2(1), pp. 44-49. Available at: http://ejournal.bsi.ac.id/jurnal/index.php/ijse/article/view/665/55 6.

[5] Supriyanti, E., Warso, M. M. and Minarsih, M. M. (2015) 'Pengaruh Kualitas Pelayanan dan Fasilitas Terhadap Kepuasan Masyarakat', Journal of Management, 1(1), pp. 0-10. Available at: http://jurnal.unpand.ac.id/index.php/MS/article/view/259.

[6] Hasanah, R. L., Kesuma, C. and Wijianto, R. (2018) 'Sistem Informasi Pelayanan Kesehatan Online Berbasis Web Pada PMI Kabupaten Purbalingga', Jurnal Evolusi, 6(2), pp. 74-83. Available at: http://ejournal.bsi.ac.id/ejurnal/index.php/evolusi/article/view/44 41.

[7] Ardhana, Kusuma. 2012. Dengan PHP:Membuat Webiste 30 Juta Rupiah. Jakarta: Jasakom.

[8] Rosa dan Shalahuddin. 2013. Rekayasa Perangkat Lunak Terstruktur dan Berorientai Objek. Bandung: Informatika Bandung.

[9] Nugraha, A. and Octasia, A. (2016) 'Sistem Informasi Penjualan Kaos Berbasis Web pada Distro Sickness Berbasis ECommerce', in SNIPTEK, pp. 299-302. Available at: http://konferensi.nusamandiri.ac.id/prosiding/index.php/sniptek/ article/view/234.

[10] Karuniawati, S., Widowati, S. and Hakim, I. L. (2015) 'Implementasi Metode Cause Effect Graphing (CEG) dalam Pengujian Pequirement Perangkat Lunak (Studi Kasus: Aplikasi G-College)', in e-Proceeding of Engineering, pp. 6475-6480. Available https://libraryeproceeding.telkomuniversity.ac.id/index.php/engi neering/article/viewFile/2967/2814.

[11] Ariyadi, B. M. and Bahar (2016) 'Model Aplikasi Sistem Pelayanan Terpadu Pada Kantor Kelurahan', Jurnal Ilmiah Teknik Informatika dan Sistem Informasi, 5(1), pp. 895-906. Available at: http://ojs.stmikbanjarbaru.ac.id/index.php/jutisi/article/viewFile/148/137\%0A.

[12] Paryanta, Sutariyani and Susilowati, D. (2017) 'Sistem Informasi Administrasi Kependudukan Berbasis Web Desa Sawahan', Indonesian Journal on Software Engineering, 3(2), pp. 77-81. Available at: http://ejournal.bsi.ac.id/ejurnal/index.php/ijse/article/view/2980.

[13] Abbas, C. J. and Novantara, P. (2016) 'Rancang Bangun Sistem Informasi Kecamatan Berbasis E-Government', Jurnal Teknologi dan Manajemen Informatika, 1(1). Available at: https://journal.uniku.ac.id/index.php/jejaring/article/viewFile/26 $6 / 205$.

[14] Ibrahim, W. H. and Maita, I. (2017) 'Sistem Informasi Pelayanan Publik Berbasis Web pada Dinas Pekerjaan Umum Kabupaten Kampar', Jurnal Ilmiah Rekayasa dan Manajemen Sistem Informasi, 3(2), pp. 17-22. Available at: http://ejournal.uin-

suska.ac.id/index.php/RMSI/article/download/4262/2618.

[15] Fahmi, I., Sulistiowati and Lemantara, J. (2015) 'Rancang Bangun Sistem Informasi Monitoring Perijinan Perusahaan Dan Industri Berbasis Web Pada Dinas Perdagangan Dan Perindustrian Kota Surabaya', Jurnal JSIKA, 4(2), pp. 1-8. Available https://jurnal.dinamika.ac.id/index.php/jsika/article/view/850. 